\title{
Origem e disseminação do Programa Bolsa Família: aproximações analíticas com o caso mexicano
}

Cristiane Kerches da Silva Leite e Ursula Dias Peres

\section{Introdução}

Na década de 1990, ocorreram mudanças importantes nas agendas governamentais dos países latino-americanos. A grande marca do período foi a formulação e a implementação de políticas econômicas de cepa neoliberal, que, segundo Moraes (2002), envolveu mais do que ajustes de balanço e corte de custos para garantir o superávit primário. Envolveu uma mudança de agenda no sentido de uma transformação dos temas, valores e paradigmas compartilhados ou "a arte de definir os termos da disputa" (Moraes, 2002, p. 20). A influência das ideias neoliberais nos paradigmas de políticas sociais se manifestou especialmente com a valorização de políticas sociais focalizadas e compensatórias como instrumento para minorar as "consequências negativas do ajuste - como o alto nível de informalidade do trabalho e o aumento do desemprego. (...) As estratégias de combate dos custos sociais das políticas neoliberais foram reduzidas à estratégia de "combater a pobreza" (UGÁ, 2004, p. 58). O Estado deveria desempenhar 
função econômica complementar e garantidora do funcionamento do mercado, por meio de políticas sociais focalizadas e compensatórias, baseadas na ideia de que indivíduos atomizados, designados como incapazes (pobres), devem ser o foco de medidas que aumentem sua "capacidade humana" (UGÁ, 2004).

Nesse sentido, o Banco Mundial promoveu, entre as décadas de 1990 e 2000, uma releitura do conceito de desenvolvimento econômico, trazendo a noção de desenvolvimento relacionada a ações de combate à pobreza e à desigualdade de renda. A perspectiva de vinculação entre pobreza e desigualdade marcou uma mudança de concepção dos organismos multilaterais, que antes se baseavam nas ideias da ortodoxia econômica, que define a desigualdade de renda como um elemento constitutivo e inescapável do desenvolvimento das economias capitalistas contemporâneas (NASCIMENTO e REIs, 2009) e, mais do que isso, imanente à realidade humana (HAYEK, 1983). Especificamente o conceito de pobreza que baseava as proposições de programas do Banco Mundial vinculavase à ideia de privação de renda, ou seja, as estratégias e experiências de combate à pobreza deveriam atacar o lado monetário dessa dimensão, com a finalidade de que os cidadãos pudessem atingir um padrão de vida mínimo (UGÁ, 2004, p. 58). Nos anos 2000, o Banco Mundial ampliou o conceito de pobreza para uma questão de privação de capacidades resultante de processos políticos, econômicos e sociais. Reconheceu-se nos relatórios que o conceito de pobreza é multidimensional e envolve condições de saúde, educação, vulnerabilidade, falta de influência e de poder. Segundo Lautier (2010), esse processo de mudança conceitual é marcado pelo crescimento da influência do ganhador do prêmio Nobel em 1998 - Amartya Sen. A mudança no vocabulário foi sintomática: de "combate à pobreza" a "combate à vulnerabilidade".

Num contexto de "ideias em movimento" e mudanças de paradigma, vários países da América Latina implementaram políticas de transferência de renda condicionada nos anos 1990 e início de 2000, inspirados em princípios de focalização de políticas públicas ${ }^{1}$. Em linhas gerais, os programas tiveram como proposta o repasse financeiro à parcela mais pobre da população, com a exigência de cumprimento de contrapartidas por parte dos beneficiados, as denominadas condicionalidades ou metas. Uma série de coalizões progressistas venceu os pleitos presidenciais de vários países da região e abriu uma janela de oportunidade política para mudanças (KIngDON, 2003). A nova agenda política, que se constituiu com a chancela de organismos multilaterais como o Banco Mundial, foi baseada em um novo conceito de desenvolvimento econômico, ou seja, o combate à pobreza e à desigualdade de renda passou a ser percebido como pré-requisito para o desenvolvimento econômico e social dos países.

O contexto das políticas sociais na região é marcado, em linhas gerais, por sistemas de proteção social incipientes e inconclusos. Enquanto na Europa as transferências universais e focalizadas coexistiram historicamente desde a implementação dos Welfare States, sendo as últimas complementares às primeiras em um contexto de universalismo extensivo, o quadro latinoamericano era outro. Nesse quadro, os programas de transferência de renda condicionada, que deveriam ser a última rede de segurança, viraram o carro-chefe entre os instrumentos de alívio da pobreza (Сово, 2012, p. 21). Desta forma, os anos 1990 
podem ser definidos como a era da focalização extensiva, na qual houve um aumento do gasto social total médio na América Latina, capitaneado pelo maior gasto em seguridade e assistência social (Coвo, 2012, p. 115). Em um contexto de crise econômica, aumento do desemprego e da pobreza, os sistemas de focalização constituíram-se como colchões ou redes de proteção, dissociados do sistema de proteção social. A focalização pela ótica da eficiência retirou o papel estabilizador e preventivo das políticas sociais (Cово, 2012, p. 22).

A escolha da análise do caso brasileiro, tendo como caso de aproximação ou referência analítica o mexicano, justificase por alguns aspectos. Se há uma grande questão que aproxima o Programa Bolsa Família do Progresa/Oportunidade é o pertencimento a uma engrenagem mais ampla, consubstanciada na estratégia de combate à pobreza, no crescimento econômico e desenvolvimento social (LEvy, 2006, p. 23). Nos dois programas, há escolhas de condicionalidades muito similares e preocupação com a lógica intergeracional da pobreza, mas as semelhanças terminam por aqui. Há diferenças bastante significativas entre esses dois programas implementados em contextos federativos e com um quadro de pobreza e desigualdade social igualmente complexo. Em primeiro lugar, há ênfases em objetivos distintos: o Bolsa Família enfatiza o alívio da pobreza via transferência monetária e lida com as corresponsabilidades de forma distinta; o Progresa/Oportunidades tem maior ênfase na quebra do ciclo intergeracional da pobreza (famílias sem filhos têm de cumprir corresponsabilidades - não há benefício sem contrapartida). No Bolsa Família, o não cumprimento de corresponsabilidades do programa implica o acionamento de um trabalhador social local, que deve apoiar a família para que ela cumpra a condicionalidade ${ }^{2}$. Entendese que o não cumprimento da corresponsabilidade é um sinal de maior vulnerabilidade da família (SOAREs, 2010, p. 159).

O contexto de políticas sociais nos dois países também é muito diverso. No caso mexicano, o Progresa/Oportunidades tende a ser sobrecarregado pelas carências do sistema de proteção social mexicano.

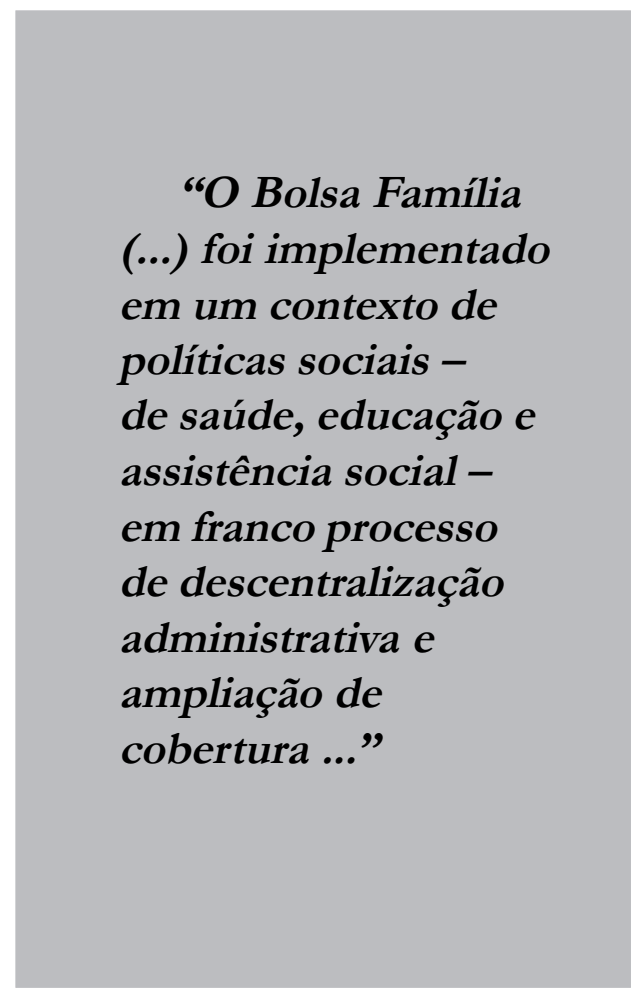

O Bolsa Família, por sua vez, foi implementado em um contexto de políticas sociais - de saúde, educação e assistência social - em franco processo de descentralização administrativa e ampliação de cobertura (Leite e Fonseca, 2011). Dessa forma, o programa seguiu uma moldura política e institucional mais ampla, com objetivos e metas próprias em cada política, 
e que já vinha historicamente acumulando bons resultados em indicadores sociais, a despeito da imensa dívida social que ainda marca a área social no Brasil ${ }^{3}$.

Objetiva-se especificamente neste texto refletir sobre o processo de formulação do programa de transferência de renda condicionada no Brasil - o Bolsa Família -, tendo o caso mexicano como espelho desse processo. Pressupomos que uma ampla adesão internacional e nacional ao paradigma dos programas de transferência de renda condicionada (PTRC) não implicou escolhas homogêneas de cursos de ação e instrumentos específicos, devido, pode-se afirmar, aos contextos políticos, sociais e institucionais idiossincráticos de aprendizagem social nos países (HALL, 1993) e às trajetórias das policies em cada país. As diferenças nas formas de formular e implementar as políticas produziram e produzem resultados distintos, a despeito da força da atuação dos organismos multilaterais em contextos históricos e institucionais específicos. Argumenta-se, neste trabalho, que a capacidade de influência dos organismos internacionais nos países é uma variável contingente não somente às condições de financiamento das políticas, mas às condições de aprendizado social, acúmulo de experiência e disseminação que se verificam na trajetória de formulação e implementação das políticas. Dessa forma, nossa "hipótese de pesquisa" é que o caso brasileiro é profundamente marcado por processos endógenos de disseminação de política, de natureza federativa, que explicam, em grande medida, as condições de formulação do Programa Bolsa Família. No caso mexicano, por sua vez, a avaliação das políticas e a coalizão econômica (TomAzıNI, 2013) legitimaram o programa de transferência condicionada, num contexto de embate de paradigmas com coloração partidária (Tomazini, 2013, p. 136).

\section{Metodologia}

Esta pesquisa caracteriza-se, quanto aos fins, como explicativa, na medida em que visa a entender as dimensões que caracterizam os processos de formulação e implementação de políticas (os contextos políticos, sociais e institucionais idiossincráticos de aprendizagem social nos países e as trajetórias das policies em cada país) e, nesses processos, a influência dos organismos multilaterais de fomento (Vergara, 1997). A estratégia analítica, quanto a essa finalidade, baseou-se em pesquisa bibliográfica e documental, além da realização de entrevistas abertas semiestruturadas com intuito descritivo do caso brasileiro.

$\mathrm{Na}$ pesquisa bibliográfica, foram levantados dados secundários sobre o caso mexicano, por meio do trabalho da Tomazini (2013). Esse trabalho tem características exploratórias e foi desenvolvido com base em várias entrevistas com atores sociais e políticos mexicanos, com intuito de ilustrar as diferenças e semelhanças com o caso brasileiro, visto que esse não é um trabalho de análise comparada, baseado em teoria comparada.

A pesquisa explicativa tem uma tipologia complexa, que busca identificar fatores determinantes de certo fenômeno, buscando razões para determinado encadeamento causal, conforme Gil (1999). Dada essa complexidade e as características do fenômeno estudado, esta pesquisa traz propostas de análise para o caso brasileiro, ilustrado pelo mexicano, sem, contudo, constituir-se em um trabalho definitivo sobre essa temática, mas, sim, em mais uma contribuição no campo da análise 
das políticas públicas, a partir da ótica teórica do neoinstitucionalismo e do pós-positivismo.

\section{Contextos, atores e ideias: arcabouço teórico}

O arcabouço conceitual desta pesquisa é formado pelos conceitos de difusão, disseminação ou transferência de políticas ${ }^{4}$ (Evans, 2006; Dolowitz e Marsh, 1996; WEYLAND, 2004), aprendizagem social (HALl, 1992) e conceitos pós-positivistas (Campbell, 2002, 1998). As premissas de análise dos autores vinculam-se às correntes teóricas do neoinstitucionalismo histórico, institucionalismo sociológico e ao pós-positivismo ${ }^{5}$. Hall (1992) é um autor neoinstitucionalista "pós-positivista" que explora o relacionamento entre novas ideias políticas e a configuração institucional, explorando a mediação entre as ideias e os resultados políticos específicos. O autor está interessado em discutir por que certas ideias (e não outras) tornam-se dominantes no discurso político. Como as ideias e os interesses interagem em contextos institucionais específicos para produzir mudanças políticas? Qual o papel do aprendizado social nesse processo? O autor argumenta que, convencionalmente,

learning is said to occur when individuals assimilate new information, including that based on past experience, and apply it to their subsequent actions. Therefore, we can define social learning as a deliberate attempt to adjust the goals or techniques of policy in response to past experience (or to policy relevant knowledge) and new information. Learning is indicated when policy changes as the result of such a process (HALL, 1993, p. 278, grifo nosso) ${ }^{6}$.
Especificamente com relação ao processo de aprendizado social, Hall (1993) argumenta que esse processo pode ser desagregado em três variáveis centrais e três ordens de mudança: as grandes metas que guiam as políticas em um campo particularos grandes paradigmas de ideias que balizam as políticas e programas; as técnicas ou instrumentos de política (ou desenho) para atingir as metas; e os conjuntos mais específicos desses instrumentos operacionais (HALL, 1993, p. 278). Situações de mudança nas quais os instrumentos operacionais mudam, mas permanecem os mesmos o desenho da política e seu paradigma basilar, Hall (1993) denomina de mudança de primeira ordem. As mudanças de segunda ordem seriam caracterizadas por mudanças no desenho da política e seus instrumentos, provocadas por experiências passadas, mesmo com a permanência do paradigma da política em questão. Por fim, quando ocorrem mudanças nos três componentes das políticas, configura-se a mudança de terceira ordem, que envolve processos para além das fronteiras dos Estados em múltiplas arenas políticas e sociais e envolvendo vários atores (HALL, 1993, p. 288). A figura 1 sintetiza os conceitos:

Campbell (2002), em sintonia com Hall (2003), define paradigmas cognitivos como análises teóricas que especificam relações de causas e efeitos, que residem na base (background) dos debates políticos e limitam o conjunto de alternativas que os policymakers percebem como úteis. As estruturas normativas - valores, atitudes, identidades -, segundo o autor, estão na base dos debates sobre políticas e constrangem ações ao limitar as alternativas que as elites percebem como sendo aceitáveis e legítimas. Normas, valores e crenças afetam suas posições sobre políticas 


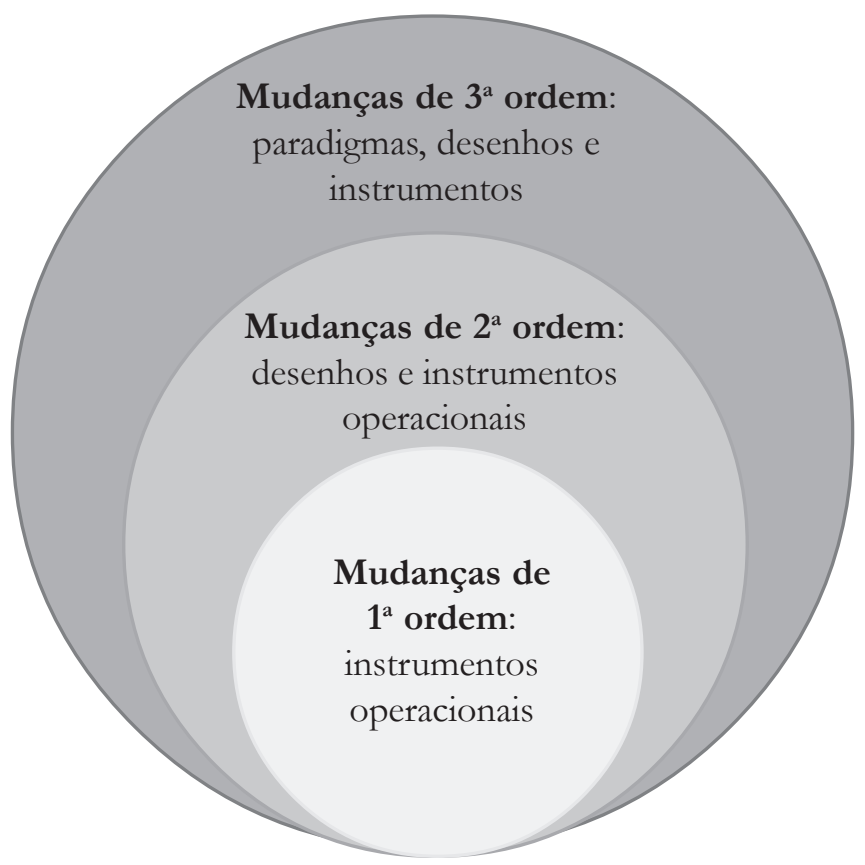

Fonte: Elaboração própria, a partir dos conceitos de Hall (1993).

\section{Figura 1: Aprendizado social e ordens de mudança política (HALL, 1993)}

públicas, ajudando-as a decidir o que é mais apropriado, especialmente em contextos em que não há uma evidência conclusiva sobre uma opção de política. Operam de acordo com uma lógica de adequação, conveniência moral e social e não por uma lógica de consequencialidade (CAMPBELL, 2002, p. 24). Enquanto estruturas normativas são as bases sociológicas e os paradigmas de políticas são estruturas interpretativas, as ideias programáticas são ideias causais precisas, que indicam como instrumentos e instituições devem ser mobilizados em situações específicas, de acordo com os princípios do paradigma estabelecido (CAmpBell, 2002, p. 28).

Weyland (2004) propõe uma análise dos processos de disseminação de políticas e programas a partir de duas categorias de transmissão de ideias: a direta e a indireta. A direta consiste na relação en- tre países sem a intermediação de organismos multilaterais, a partir de rotas de similaridades. Se, por um lado, a transmissão direta aumenta a chance da aplicabilidade das políticas pela similaridade, por outro, pode negligenciar experiências interessantes "off the beaten track" (Weyland, 2004, p. 14). A forma indireta se dá a partir da atuação de "promotores" de modelos - think tanks, centros de pesquisa, organizações internacionais, como o Banco Mundial e a Organização Internacional do Trabalho (OIT). O autor cita que a importância da atuação desses atores se dá centralmente em virtude da disseminação de experiências inovadoras de países isolados, que não se configuram como aqueles de "alto status". Exemplo disso é o caso da Nova Zelândia, cuja experiência de responsabilidade fiscal foi importada por vários países, inclusive o 
Brasil. Dessa forma, as instituições promoveriam um olhar para além dos países com rotas similares.

Contudo, há uma série de riscos nos processos de transmissão indireta. Em primeiro lugar, modelos propostos pelos organismos internacionais podem partir da crença falaciosa de que existe um modelo de validade universal para todos os países. A partir desse pressuposto, pode-se incorrer em uma excessiva uniformidade nas recomendações políticas dos organismos, ignorando-se o fato inconteste de que experiências aplicadas em um país podem ser inaplicáveis em outros. Em segundo lugar, há o grande risco de incorrerem em ideological blinders (WEYLAND, 2004, p. 13), baseada em orientação teóriconormativa das instituições, que selecionam as experiências dos países que serão bases para os modelos a serem disseminados a partir de suas próprias agendas políticoideológicas. Esse risco é ainda mais premente diante do deslocamento do eixo de influência de ideias das políticas governamentais nas últimas décadas, da academia para os organismos multilaterais (DEACON, 2000).

Por fim, e não menos importante, trata-se do risco da submissão dos países com carência de recursos para o financiamento de políticas ao poder dos organismos multilaterais, que comandam suntuosos montantes de recursos e utilizam a abertura de canais de empréstimo, de forma bastante empoderada, para "transmitirem" as suas ideias pelo mundo. Predominaria o jogo da pressão política das organizações, mormente o FMI e o Banco Mundial, nos contextos nacionais, em contraste com as novas formas de governança das políticas públicas baseadas em pactuação e deliberação entre atores políticos e sociais estratégicos.
Neste trabalho, verificamos, por meio das entrevistas, que esse risco é factível nos casos latino-americanos abordados, mas predomina em condições políticas muito específicas, que envolvem problemas orçamentários dos entes governamentais e condições de alinhamento ideológico dos governos com as instituições promotoras dos modelos.

Os quadros 1 e 2 sintetizam a contribuição dos conceitos pós-positivistas de

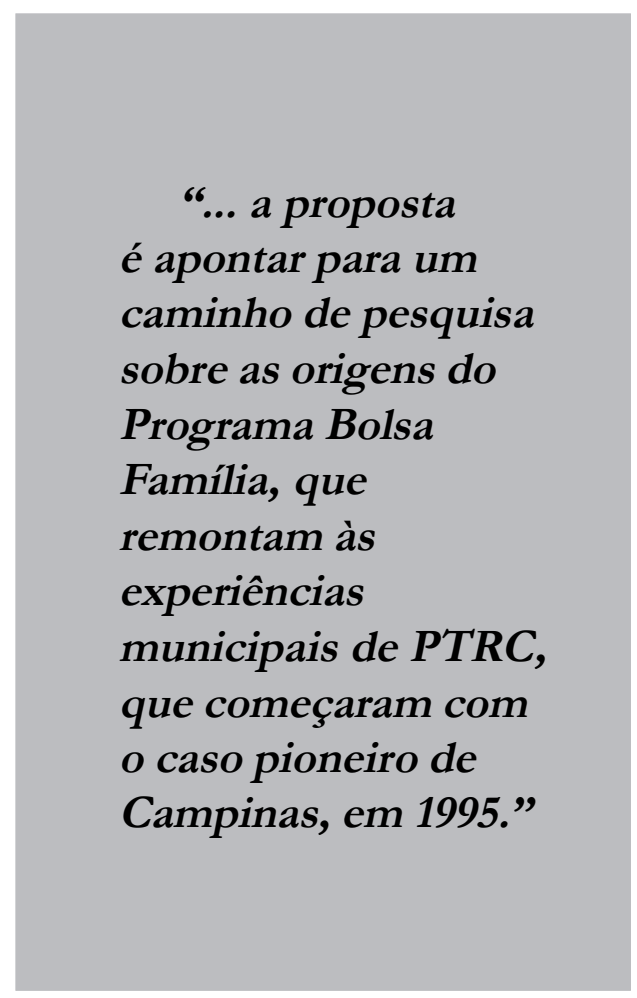

Campbell (2002): estrutura normativa, paradigma cognitivo e ideias programáticas; e a categorização de mecanismos de disseminação de ideias de políticas públicas em Weyland (2004).

Pode-se afirmar que um elemento comum, estruturante da "onda" de inovação em políticas de combate à pobreza, que atingiu vários países da América 
Latina ou, nos termos de Hall (1993), a estrutura interpretativa básica de formulação de soluções para o problema da fome e da desigualdade de renda foi o paradigma focalizador de programas de transferência de renda (PTR). Soares (2010) argumenta que há dois objetivos e três características básicas que identificam esses programas. Os objetivos são "o alívio da pobreza em curto prazo e a quebra da transmissão intergeracional da pobreza em longo prazo" (SoARES, 2010, p. 140). As três características básicas são: i) a existência de mecanismos de focalização; ii) as exigências de contrapartidas, por parte das famílias, para que possam receber o benefício, as chamadas corresponsabilidades, mormente nas áreas de saúde e educação, para estimular a acumulação de capital humano das crianças; e iii) o fato de o benefício ser pago em dinheiro. "A esse conjunto de características podem-se

\section{Quadro 1: Arcabouço conceitual analítico pós positivista (CAMPBELL, 2002)}

\begin{tabular}{|l|l|}
\hline $\begin{array}{l}\text { Valores, atitudes e crenças: estruturas } \\
\text { normativas }\end{array}$ & $\begin{array}{l}\text { Legitimidade da agenda de combate à } \\
\text { pobreza }\end{array}$ \\
\hline $\begin{array}{l}\text { Paradigmas cognitivos: estruturas } \\
\text { interpretativas }\end{array}$ & $\begin{array}{l}\text { Capital humano, segurança alimentar e renda } \\
\text { incondicionada (Tomazini, 2013) }\end{array}$ \\
\hline $\begin{array}{l}\text { Ideias programáticas: desenhos e instru- } \\
\text { mentos específicos das policies }\end{array}$ & $\begin{array}{l}\text { Mecanismos de focalização: contrapartidas } \\
\text { e benefício em dinheiro }\end{array}$ \\
\hline
\end{tabular}

Fonte: Elaboração própria.

Quadro 2: Mecanismos de disseminação de ideias de políticas e programas (WEYLAND, 2004)

\begin{tabular}{|l|l|}
\hline \multicolumn{2}{|c|}{ Como informações e conceitos dos modelos são disseminados? } \\
\hline Transmissão Direta & $\begin{array}{l}\text { Consiste na relação entre países sem a intermediação de organismos } \\
\text { multilaterais, a partir de rotas de similaridades partilhadas, de } \\
\text { ordem econômica, social, cultural e histórica entre países. }\end{array}$ \\
\hline Transmissão Indireta & $\begin{array}{l}\text { Atuação de "promotores" de modelos - think tanks, centros de } \\
\text { pesquisa, organizações internacionais, como o Banco Mundial } \\
\text { e a OIT. }\end{array}$ \\
& $\begin{array}{l}\text { Riscos: } \\
\text { - crença falaciosa de validade universal para todos os países; } \\
\text { - ideological blinders baseada em orientação teórico-normativa das } \\
\text { instituições; } \\
\text { - submissão dos países com carência de recursos. }\end{array}$ \\
\hline
\end{tabular}

Fonte: Elaboração própria. 
somar as seguintes especificidades que estão inter-relacionadas: o fato de o titular do benefício ser, em geral, a mãe ou a mulher responsável pela criança e um foco no bem-estar das crianças" (SOAREs, 2010, p. 140).

\section{Trajetórias históricas e aprendi} zado social: aspectos dos casos brasileiro e mexicano

Analisando as duas últimas décadas das trajetórias históricas das políticas e programas de transferência de renda nos dois países, podem ser destacados alguns eventos importantes que sugerem pontos de similaridades e diferenças entre os processos de formulação dos programas. Optou-se por desenvolver uma análise da trajetória histórica dos países identificando períodos no tempo, em vez de analisar os casos separadamente.

As trajetórias históricas dos programas de transferência de renda no Brasil e no México na década de 1990 possuem pontos de contato interessantes analiticamente para a reflexão sobre os processos de disseminação de ideias que envolvem os dois países. Neste trabalho, mais do que explorar pontos de disseminação entre os países, a proposta é apontar para um caminho de pesquisa sobre as origens do Programa Bolsa Família, que remontam às experiências municipais de PTRC, que começaram com o caso pioneiro de Campinas, em $1995^{\circ}$. Vale destacar que, como indicado no Quadro 3, as primeiras experiências municipais no Brasil são anteriores à implementação do Progresa mexicano em 1997, o que reforça nossa hipótese sobre o caráter endógeno do processo brasileiro, pelo menos com relação à influência mexicana. No entanto, em se tratando de experiências pioneiras nacionais de implementação de programas de transferência de renda condicionada no mundo, o Progresa deve ser destacado.

\section{Década de 1990: a antessala da} criação dos programas de transferên $\square$ cia de renda

No Brasil, Silva (2007) considera como um primeiro ponto de inflexão na agenda da transferência de renda a apresentação e aprovação, no Senado Federal, do Projeto de Lei no 80/1991, do senador petista Eduardo Suplicy, propondo o Programa de Garantia de Renda Mínima (PGRM). Esse programa destinava-se a beneficiar todos os brasileiros residentes no País, maiores de 25 anos de idade, com uma renda que correspondesse a 2,25 salários mínimos, em valores de 2005 (Silva, 2007, p. 1431). Naquela época, iniciou-se uma discussão em torno da articulação entre renda mínima familiar e educação, visando ao combate da pobreza e seus processos de reprodução.

Além desse debate, o paradigma da segurança alimentar também pautou a discussão, à época, por alternativas políticas de combate à fome, à pobreza e à exclusão social. A criação da ONG Ação para Cidadania contra a Fome, a Miséria e pela Vida, liderada pelo sociólogo Herbert de Souza (Betinho), foi um marco que, inclusive, deu centralidade ao paradigma de segurança alimentar no debate das políticas sociais, na formulação do programa de governo do então candidato Lula no início dos anos 2000 (Сово, 2012, p. 151).

A década de 1990 foi um importante período de antessala no processo de criação dos programas, conforme argumenta Tomazini (2013). Segundo a autora, entre 1991 e 1997, houve intenso debate sobre programas de combate à pobreza nos países, a implementação de programaspiloto de transferência condicionada no 


\section{Quadro 3: Trajetórias históricas em comparação: pontos de contato}

\begin{tabular}{|c|c|}
\hline Brasil & México \\
\hline $\begin{array}{l}\text { 1991: apresentação e aprovação no Senado } \\
\text { Federal do Projeto de Lei nº 80/1991 do } \\
\text { senador Eduardo Suplicy, propondo o } \\
\text { Programa de Garantia de Renda Mínima } \\
\text { (PGRM). } \\
\text { - Segurança alimentar na agenda pública: } \\
\text { Ação da Cidadania contra a Fome, a Miséria } \\
\text { e pela Vida, movimento liderado pelo } \\
\text { Betinho. }\end{array}$ & $\begin{array}{l}\text { 1989-1994: Programa Nacional de } \\
\text { Solidariedad (Pronasol) - focalização das } \\
\text { ações do programa na população pobre e } \\
\text { indígena. }\end{array}$ \\
\hline $\begin{array}{l}\text { 1995: experiências municipais em Campinas } \\
\text { (pioneira), Santos, Ribeirão Preto (Estado de } \\
\text { São Paulo) e em Brasília (Distrito Federal). } \\
\text { 1996: primeiras experiências de iniciativa do } \\
\text { Governo Federal (Bolsa Escola, Cartão } \\
\text { Alimentação, Auxílio Gás e Bolsa Alimen- } \\
\text { tação); criação do Programa de Erradicação } \\
\text { do Trabalho Infantil (Peti) e início da } \\
\text { implementação do Benefício de Prestação } \\
\text { Continuada (BPC) instituído pela Lei Orgâ- } \\
\text { nica da Assistência Social (LOAS). }\end{array}$ & $\begin{array}{l}\text { 1997: Progresa (Programa de Educação, Saúde e } \\
\text { Alimentação), antecessor do programa } \\
\text { Oportunidades, foi concebido de maneira } \\
\text { intersetorial, com foco na acumulação de } \\
\text { capital humano e como um meio de acesso } \\
\text { aos direitos à saúde, à educação básica e à } \\
\text { alimentação adequada, para romper com o } \\
\text { ciclo de transmissão da pobreza. }\end{array}$ \\
\hline $\begin{array}{l}\text { 1999: Comissão Mista Especial do Con- } \\
\text { gresso Nacional: proposição de uma emenda } \\
\text { constitucional que originou o Fundo de } \\
\text { Combate e Erradicação da Pobreza. }\end{array}$ & $\begin{array}{l}\text { 2000: divulgação de uma avaliação positiva } \\
\text { do Progresa, realizada pelo International Food } \\
\text { Policy Research Institute (IFPRI), marcou a } \\
\text { formação de uma massa crítica internacional } \\
\text { em torno da proposta de transferência de } \\
\text { renda condicionada. }\end{array}$ \\
\hline $\begin{array}{l}\text { 2001: Prefeitura Municipal de São Paulo, } \\
\text { gestão Marta Suplicy - implementação de } \\
\text { quatro programas redistributivos; entre eles, } \\
\text { o de Garantia de Renda Familiar Mínima } \\
\text { (PGRFM) }\end{array}$ & 2001: Oportunidades - ampliação do Progresa \\
\hline $\begin{array}{l}\text { 2003: Programa Nacional de Acesso à Ali- } \\
\text { mentação (PNAA) - implementação do } \\
\text { Fome Zero } \\
\text { 2003: Implementação do Programa Bolsa } \\
\text { Família 2004: criação do Ministério de } \\
\text { Desenvolvimento Social }\end{array}$ & \\
\hline
\end{tabular}

Fonte: Elaboração própria. 
México e no Distrito Federal (Brasil) e de programas municipais, assim como a formulação de dispositivos federais em ambos os países (Tomazini, 2013, p. 128). Contudo, um ponto de comparação dos casos brasileiro e mexicano nos anos 1990 deve ser enfatizado. Enquanto no Brasil a aprovação do PGRM do senador Eduardo Suplicy marcou a discussão de um programa de renda incondicionada, no México, desde aquele período, as primeiras propostas de transferência monetária nasceram condicionadas (TomAZINI, 2013):

Em 1991, o livro "Poverty alleviation in Mexico" de Santiago Levy lançou as bases de uma proposta de transferência de renda condicionada. (...) A coalizão que reúne os defensores do 'capital humano' no México se forma a partir das considerações e avaliações sobre o conjunto de programas direcionados à população pobre: o Programa Nacional de Solidaridad (Pronasol) (Tomazini, 2013, p. 123).

A experiência do Pronasol entre 19891994 evidencia um processo de aprendizado endógeno no caso mexicano, que consistiu na focalização das ações do programa na população pobre e indígena, ênfase na descentralização e na participação das comunidades e o aumento do orçamento dedicado ao desenvolvimento social. Além desses aspectos, um de seus componentes, o Niños en Solidariedad, foi um antecedente importante para o desenho do Progresa/Oportunidades, uma vez que o programa oferecia bolsas de estudos para crianças pobres que frequentassem a escola, apesar da cobertura muito limitada (SOARES, 2010, p. 143).

Na perspectiva do aprendizado social, como proposto por Hall (1993), as expe- riências municipais de Campinas, Ribeirão Preto e Santos (no Estado de São Paulo) e a experiência do Programa Bolsa Escola em Brasília (Distrito Federal), em meados da década de 1990 no Brasil, são interessantes para refletir sobre o aprendizado de um grupo de técnicos e políticos municipais, que se difundiu para além das

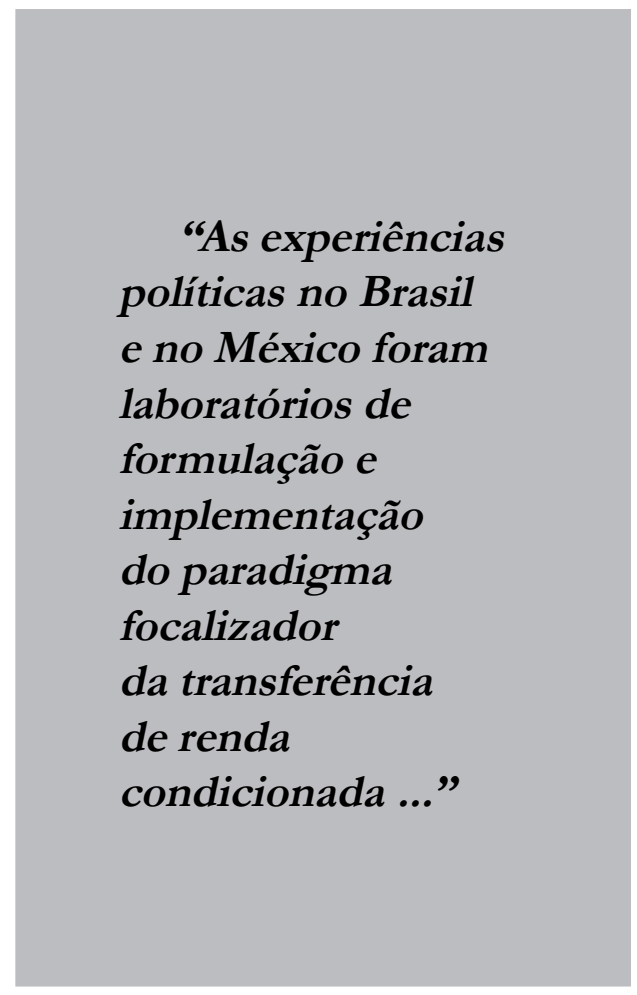

fronteiras das municipalidades, disseminando-se em comunidades políticas e epistêmicas que, quase uma década depois, participariam ativamente do debate da formatação do Programa Bolsa Família. Fonseca (2012) destaca o programa de Campinas - o pioneiro no País, que iniciou os pagamentos em março de 1995 -, o programa do Distrito Federal (Governo Cristovão Buarque), Ribeirão Preto (similar ao de Campinas), Salvador e Vitória como experiências 
brasileiras importantes anteriores ao programa mexicano Progresa. Em Campinas, a motivação inicial do PTRC foi vinculada à temática da segurança alimentar. O fenômeno da desnutrição passou a ter notificação compulsória, assim como as doenças infectocontagiosas, no contexto da campanha de combate à fome do Betinho. Embora o mote tenha sido de segurança alimentar, foram instituídas condicionalidades vinculadas à saúde e à educação (FONSECA, 2012). Vale ressaltar que esses municípios, pioneiros na promoção de experiências de renda mínima, apresentavam indicadores mais elevados de renda per capita e desenvolvimento humano que a média nacional e, dessa forma, não se verificou nesses o debate que marcou o contexto internacional, associando crise econômica e ajuste fiscal a políticas sociais compensatórias. Em 1996, foram iniciadas as primeiras experiências de iniciativa do Governo Federal brasileiro, com a criação do Programa de Erradicação do Trabalho Infantil (Peti) e com o início da implementação do Benefício de Prestação Continuada (BPC) instituído pela Lei Orgânica da Assistência Social (LOAS). Enquanto no Brasil as estruturas das políticas de assistência social desenvolviam-se consistentemente em direção a um paradigma de direitos sociais, no México agravava-se a percepção de problemas nos programas de subsídio alimentar, que estavam estruturados em um quadro administrativo complexo. Havia 15 programas de subsídio alimentar, a cargo de 10 secretarias e organismos distintos. Problemas de ordem administrativa, falta de coordenação entre os órgãos gestores e dispersão demográfica dos beneficiários apontavam para a necessidade de mudanças. Segundo Levy
(2006, p.5), havia, por exemplo, um desequilíbrio entre os territórios com maior concentração de população pobre (meio rural) e a alocação de recursos orçamentários (que privilegiava o meio urbano), além da ineficiência do sistema de subsídios alimentares em função da dispersão populacional.

Em 1997, no México, o Programa de Educação, Saúde e Alimentação (Progresa), antecessor do programa Oportunidades, foi concebido de maneira intersetorial, com foco na acumulação de capital humano e como um meio de acesso aos direitos à saúde, à educação básica e à alimentação adequada, para romper com o ciclo de transmissão da pobreza (FONSECA e VIANA, 2007, p. 1507). Pode-se afirmar que foi uma mudança importante, de $2^{\mathrm{a}}$ ordem nos termos de Hall (1993). A partir do paradigma de combate à pobreza via focalização, que já vinha se desenvolvendo no México há alguns anos, migrou-se de um sistema de subsídio de alimentos, em que os pobres recebiam pela condição de ser pobres, para outro em que se delegava maior responsabilidade para atuar, no sentido de receberem as transferências e maior liberdade para decidirem como deveriam gastá-las. O enfoque no desenvolvimento das "capacidades das pessoas" a partir do investimento do capital humano das crianças, com a garantia de acesso à educação, saúde e nutrição adequada, representava um alinhamento com objetivos de longo prazo de um programa de transferência de renda condicionada (PTRC), completando uma trinca de características: focalização, transferência de dinheiro e existência de corresponsabilidades a serem exigidas das famílias (SOARES, 2010, p. 177).

Segundo Tomazini (2013), o panorama político que marcou a ascensão do paradigma do capital humano no México 
era de disputa entre a coalizão dos "reformadores sociais" e dos "tecnocratas" da área econômica.

O futuro da Sedesol (Secretaria de Desenvolvimento Social) e do Pronasol era um assunto bastante sensível no início da administração Zedillo (Valencia Lomelí, 2003). As diferenças entre os "tecnocratas" e "reformadores sociais" eram exacerbadas entre as equipes do Ministério das Finanças e da Sedesol. Esse conflito foi resolvido com a tentativa de atrelar as políticas de combate à pobreza com as reformas econômicas que estavam sendo implementadas na perspectiva do capital humano (LEVY, 2004) (Tomazini, 2013, p. 129).

Configurou-se, dessa forma, um alinhamento político entre atores políticos estratégicos - em outras palavras, uma coalizão - e um contexto político favorável à hegemonia do ideário do capital humano no México, no qual especialistas (Santiago Levy), think tanks (Banco Mundial), empreendedores políticos (o próprio Presidente Zedillo e seu gabinete) e a agenda econômica de abertura comercial sustentavam a formulação de políticas com base nesse arcabouço epistêmico.

Nesse mesmo diapasão, observa-se no caso mexicano que a viabilização da disseminação da experiência também se deu em virtude do uso de informação primária e técnicas estatísticas, seja para selecionar os beneficiários, seja para implementar um sistema de avaliação de impacto de natureza experimental que inovou e provocou impactos internos, consolidando o programa e criando condições técnicas para a sua continuidade ${ }^{9}$. Além dos impactos internos, do ponto de vista externo, as avaliações de impacto sistemáticas foram veículos de divulgação legitimados pelo crivo científico da metodologia experimental, reconhecido pelo aparato técnico dos países e dos organismos multilaterais como fonte qualificada de informações sobre resultados, impactos e efeitos dos programas entre outros países. Num contexto em que outros países latino-americanos discutiam a pertinência dos programas de transferência de renda, a circulação de informações sobre robustas avaliações de impacto do caso mexicano foi importante no processo de formatação dos programas de outros países, como o Brasil, por exemplo (SOARES, 2010, p. 145).

No final dos anos 1990, iniciou-se um período de mudanças importantes no contexto brasileiro, marcado por um clima nacional e internacional (KInGDON, 2003) propício à formulação e implementação de programas de transferência de renda condicionada no plano federal. Em 1999, a Comissão Mista Especial do Congresso Nacional propôs uma emenda constitucional que originou o Fundo de Combate e Erradicação da Pobreza. Os debates e as audiências públicas que marcaram o processo decisório ocorrido na comissão ajudaram a criar um consenso político em torno da ideia de que os programas de transferência de renda condicionada seriam o melhor curso de ação para combater a pobreza no País (SOARES, 2010, p. 182).

\section{A virada política dos anos 2000}

Em 2000, a divulgação de uma avaliação positiva do Progresa, realizada pelo International Food Policy Research Institute (IFPRI), marcou a formação de uma massa crítica internacional em torno da proposta de transferência de renda condicionada. Acadêmicos e bancos de desenvolvimento 
mobilizaram-se por meio de publicações e relatórios, enaltecendo as experiências mexicana e brasileira, entre outras (LAUTIER, 2010, p. 362).

No penúltimo ano do segundo mandato do Governo Cardoso (2001), ocorreu uma expansão dos programas de iniciativa do Governo Federal brasileiro em desenvolvimento e a criação de novos, com destaque ao Programa Bolsa Escola e ao Programa Bolsa Alimentação. Esses programas já apresentavam características que depois foram aperfeiçoadas no Bolsa Família, como a implementação descentralizada, com foco na mobilização de equipamentos municipais, abrangendo a grande maioria dos mais de 5.560 Municípios brasileiros.

Em 2001, iniciou-se o processo de formulação e implementação do Programa de Renda Mínima da Prefeitura Municipal de São Paulo. Destaca-se essa experiência na perspectiva de análise deste texto, pois o mesmo grupo que coordenou o programa no Município de São Paulo em 2001 participou de dois momentos cruciais no Governo Federal: a unificação do Programa Bolsa Família, em 2003, e a implementação de uma importante mudança recente do programa, o Brasil sem Miséria, em 2011. Ana Fonseca, que coordenou o Programa Bolsa Família entre 2003 e 2004 e foi Secretária Executiva do Ministério do Desenvolvimento Social, em 2004, foi coordenadora do programa municipal de renda mínima no governo de Marta Suplicy (2001 2004). No contexto daquele governo, Ana Fonseca era um ator externo, de grande respaldo acadêmico e técnico, convidada de fora da rede política da capital para formular e implementar o programa de renda mínima, e que desenhou uma estratégia de implementação marcada por intensa negociação com os grupos epistêmicos e políticos do governo ligados a políticas redistributivas e emancipatórias ${ }^{10}$, os burocratas da máquina administrativa e os potenciais beneficiários elegíveis das regiões mais vulneráveis da cidade (Pochmann, 2002). Havia um conflito no governo, na ocasião, entre os grupos do partido (Partido dos Trabalhadores), que competiam por orçamento e discordavam quanto ao paradigma cognitivo sobre desenvolvimento $^{11}$, argumentando que o investimento em renda mínima não redundaria em desenvolvimento econômico, conceito esse que mudou anos depois com a implementação do Programa Bolsa Família e foi aprofundado com o Brasil sem Miséria $^{12}$ (FonseCA, 2012). Também nesse período de 2001, houve tentativas de negociação da unificação dos programas de diferentes níveis de governo por parte do grupo do Município, já que havia o Programa Renda Cidadã no governo estadual e bolsas pulverizadas no Governo Federal (Bolsa Escola, Bolsa Alimentação, Vale Gás e Cartão Alimentação).

Em 2003, no início do Governo Lula, a agenda política de combate à fome se consolidou no Brasil, liderada pela equipe de José Graziano. Havia cinco programas de transferência de renda condicionada em curso (os supracitados, além do Programa de Erradicação do Trabalho Infantil - Peti) e, em fevereiro de 2003, o governo recémempossado criou o Programa Nacional de Acesso à Alimentação (PNAA), sob a responsabilidade do recém-criado Ministério Extraordinário da Segurança Alimentar (Mesa) (SOARES, 2010, p. 182). O objetivo do ministério era implementar o Fome Zero, desenvolvido em 2001 pelo Instituto Cidadania, organização não governamental ligada ao PT. No mesmo ano, em outubro, ocorreu a unificação dos programas de transferência de renda 
(integrando, posteriormente, o Peti) no Programa Bolsa Família, processo esse liderado pela Ana Fonseca, então Secretária Executiva do MDS. As propostas foram de unificação das bolsas e pactuação dos três níveis de governo na implementação do programa, sob a coordenação federal, mas não foram de imediato acolhidas politicamente. Num primeiro momento, houve divergência entre o grupo do Ministério Extraordinário de Segurança Alimentar e Nutricional (José Graziano) e o grupo da Ana Fonseca, que propunha a unificação de todas as bolsas. Esse grupo sai do governo e volta no mesmo ano, num momento em que já havia grupos políticos vinculados a cada "bolsa", o que tornava difícil o processo de unificação dos programas, com debates intensos entre os grupos do mesmo partido, como o debate sobre a frequência escolar como condicionalidade de um programa unificado $^{13}$. Em 2004, foi criado o Ministério do Desenvolvimento Social, trazendo no seu bojo a discussão do Cadastro Único.

Observando em retrospectiva esse processo, é notável a rapidez em que se desenvolveram arranjos políticos e institucionais ligados à assistência social e ao combate à pobreza no Governo Federal brasileiro, no início da década de 2000. No entanto, deve-se observar que se trata de um processo moldado por componentes históricos de claro aprendizado social, beneficiado por experiências e conhecimentos acumulados em um horizonte temporal: a história da própria política de assistência e combate à fome em várias instâncias de governo durante a década de 1990, a mobilização secular de grupos ligados ao movimento sanitarista e de assistência social que desembocou na Constituição de 1988, a massa crítica formada por atores políticos e sociais com capilaridade nacional e internacional que vinha discutindo conceitos, desenhos e instrumentos de políticas e que contribuiu para criar um contexto favorável ao desenvolvimento da agenda de combate à pobreza no Brasil e em vários países latinoamericanos. Pode-se afirmar, a partir das entrevistas realizadas, que as experiências como pesquisadora e coordenadora da Ana Fonseca e sua equipe em diferentes programas nas instâncias municipais e federal foram a correia de transmissão de um processo de disseminação de experiências que marcaram o desenvolvimento do programa federal, conforme Dolowitz e Marsh (1996) citados por Farah (2008), transferindo desenhos de políticas, práticas de mobilização de stakeholders, arranjos administrativos, instituições etc. Verifica-se, nesse processo brasileiro, o embate de dois paradigmas cognitivos, a segurança alimentar e o capital humano, cujas coalizões políticas que os sustentavam marcaram um processo de disputa orçamentária e espaço institucional (Tomazini, 2013, p. 135).

Especificamente nos casos do Brasil e do México, os contextos do desenvolvimento do Bolsa Família e do Progresa/Opor tunidades foram bem distintos. O México, na década de 1990, passava por grave crise econômica, crise política, levante dos Chiapas, configurando-se um período extremamente turbulento. Nesse contexto, criou-se um consenso entre atores políticos e sociais mexicanos em torno do diagnóstico dos impactos negativos da crise entre os mais pobres. No entanto, um dissenso marcou a interação entre os órgãos de governo quanto ao melhor curso de ação a ser decidido. Segundo Levy (2006, p. 16), a síntese é que se tratava de um contexto propício de mudança - novo governo, clima político favorável, acúmulo de evidências empíricas e experiência administrativa. 
O consenso na agenda de combate à pobreza foi chancelado pelo Presidente Zedillo e pela Secretaria da Fazenda, que reconhecia nas mudanças a serem realizadas a oportunidade de centralizar o controle do orçamento das políticas sociais.

No Brasil, o Governo Cardoso iniciou um processo de criação de programas de transferência de renda federais, que ganhou maior impulso no Governo Lula. Em seu primeiro ano de mandato, o Governo Lula se encontrava com força política para iniciar, pode-se dizer, um processo de ressignificação da agenda de combate à fome e à pobreza no Governo Federal, caracterizado por uma nova articulação com o arcabouço de políticas sociais e econômicas já desenvolvidas no País desde a década de 1990 e expandindo a magnitude dessas políticas dentro do governo ${ }^{14}$.

\section{Considerações finais}

As experiências políticas no Brasil e no México foram laboratórios de formulação e implementação do paradigma focalizador da transferência de renda condicionada e, ao mesmo tempo, propagadoras de influência, seja via transmissão direta, seja via transmissão indireta (WEYLAND, 2004). Difundido e multiplicado internacionalmente, o paradigma foi também retroalimentado por experiências nacionais, em processos de adaptação de elementos de primeira e segunda ordem (HALL, 2003) em contextos de ideias normativas e processos políticos e sociais que ressignificaram os programas em cada contexto nacional (CAmpbell, 1998).

Com relação à transmissão indireta, pode-se dizer que o Banco Mundial influenciou os países ao repercutir o paradigma focalizador de transferência de renda condicionada, mas também sofreu influência. Conforme relato dos entrevistados (Quiroga, 2011; Ossandon e Urriola, 2011; FonseCA, 2012), pode-se afirmar que a implementação dos programas brasileiro e mexicano foi marcada por um processo de aprendizado "cruzado", em que os países latino-americanos receberam influências de primeira e segunda ordem (Hall, 1993) do Banco Mundial, na medida em que os técnicos da instituição recomendaram ajustes na implementação, como acertos em cobertura, condicionalidades e outros. Essas recomendações tiveram maior influência política em contextos favoráveis marcados por um alinhamento paradigmático e de interesses, conforme analisado no final dos anos 1990 no México. No entanto, o próprio organismo também sofreu influência, na medida em que acumula o aprendizado de um país ao acompanhar a execução de um programa. A instituição influenciou a percepção internacional sobre determinada área de política social, agindo como caixa de ressonância ao repercutir a política em países e regiões não necessariamente similares aos países de origem, conforme apontado em Weyland (2004). As entrevistas citaram a existência de uma rede internacional de cooperação, na qual os técnicos dos países que desenvolvem PTRC trocam experiências, com a presença de técnicos do Banco Mundial e de outras instituições internacionais.

O modelo brasileiro, em contraste com o mexicano, apresenta cobertura substancialmente maior, dadas as características geográficas e sociais do País. O Bolsa Família brasileiro, ao atender 12 milhões de famílias, conseguiu massificar o focalismo de seu modelo, gerando, com isso, impactos econômicos de grande repercussão. Esses impactos tornaram-se alvo da atenção internacional e reforçaram a 
importância do alargamento de sua base. As entrevistas sugerem, dessa forma, que o modelo mexicano que se consolidou entre 1997 e 2001 e a atuação do Banco Mundial, divulgando os bons resultados da experiência, criaram um clima político favorável à formulação de alternativas de políticas de combate à pobreza e desigualdade no Brasil nos moldes da transferência de renda condicionada. Dulci (2009) avalia que a política de transferência de renda desenhada no México foi uma ferramenta de aprendizagem para outros países da América Latina e instituições internacionais (Dulci, 2009, p. 7).

Contudo, a implementação do caso brasileiro tornou-se um modelo de programa via mecanismos diretos - as várias missões internacionais que vieram ao Brasil para conhecer o programa - e indiretos - atuação do Banco Mundial, que assumiu o caso brasileiro como um caso a ser replicável em outros países, sejam similares ou distintos ao Brasil (WEYLAND, 2004). Comparado com o brasileiro, o Oportunidades é um programa que mais se aproxima dos paradigmas dos modelos de programas de transferência de renda do BIRD e do Banco Mundial ${ }^{15}$. Interessante pontuar que o programa mexicano recebeu o maior empréstimo da história do Banco Interamericano de Desenvolvimento (BID) para a expansão dos programas nas áreas urbanas (Dulci, 2009), o que indica a dimensão histórica e potencial do programa mexicano para a América Latina.

$\mathrm{Na}$ análise da formulação do Programa Bolsa Família, é fundamental destacar que a construção do programa passa, em grande medida, pela trajetória de políticas anteriores de transferência de renda (HALL, 1992), visto que, no momento em que a União organiza e consolida os PTRC federais, havia já em funcionamento diferentes programas municipais de transferência de renda (São Paulo, Campinas, Ribeirão Preto) e estaduais (Distrito Federal, entre outros), conforme abordado, e esses modelos são nacionalizados no processo de construção da amplitude do Programa Bolsa Família.

Quiroga (2011) e Sposati (2011) destacaram as experiências do Programa para a Erradicação do Trabalho Infantil e, especialmente, do Programa Bolsa Escola. Fonseca (2012) destacou a experiência do Programa Renda Mínima no Município de São Paulo como fundamental para a escolha da priorização do Programa Bolsa Família na agenda do primeiro mandato do Governo Lula. Foi uma experiência em uma escala inédita no Brasil, que deu visibilidade ao processo e aos resultados do programa. O caso de São Paulo tornou-se "modelo" de renda mínima no Brasil, legitimado por técnicos do Banco Mundial e do BID, nos termos de Weyland (2004), seguido pelo Governo Federal. A escolha técnica da equipe da Ana Fonseca foi, na realidade, uma escolha política. O Banco Mundial e o BID ganharam uma "grife" atrelada a um governo progressista, que descolava os PTRC dos paradigmas mais conservadores, e o Governo Federal trazia um grupo responsável por uma experiência conhecida internacionalmente, que legitimava o processo de unificação do Bolsa Família. Nos dois casos, há elementos importantes de aprendizado social (HALL, 1993). Os atores políticos e sociais trazem para suas práticas decisórias do presente percepções e aprendizados de experiências políticas do passado.

Nos anos 2000, a implementação do Programa Bolsa Família ocorreu pari passu com a implementação de um modelo sistêmico para a assistência social, o Sistema Único de Assistência Social 
(SUAS). Vale comentar que são processos de políticas sociais que se reforçam, a despeito da existência de fundos de recursos distintos: o Fundo Nacional da Assistência Social (FNAS) ligado ao SUAS e o Fundo de Erradicação da Pobreza que provê a maior parte dos recursos do Bolsa Família. O PBF tem se mostrado no Brasil um programa em movimento, em que famílias entram e saem constantemente, dependendo da sua condição social. O SUAS tem abarcado as famílias em uma rede de cuidado que vai além do PBF, o que diferencia o PTRC brasileiro do mexicano por sua inserção/convivência em uma política mais global e sistêmica de assistência social.

Por fim, procurou-se discutir neste texto os caminhos da inovação de políticas sociais no Brasil, tendo como espelho o caso do México (mas que também se verificaram em outros países latino-americanos), especificamente os programas de transferência de renda, que envolveram processos complexos e multifacetados, pois não foram, em grande medida, definidos estruturalmente por meio da atuação dos organismos multilaterais, mas explicados por matrizes de correlação entre atores e instituições com relações dinâmicas, dentro de molduras políticas, institucionais e culturais de cada país (dentro das quais a atuação dos organismos multilaterais se inseriu). Não se nega aqui o peso dos organismos internacionais, especialmente os financeiros, nos processos de formulação e implementação de políticas, mas propõese uma análise mediada por aspectos históricos, econômicos, políticos e institucionais, com a valorização do olhar teórico neoinstitucionalista e das teorias de políticas públicas pós-positivistas, que podem iluminar as abordagens de futuros estudos sobre outras políticas setoriais e sobre outros aspectos da política de combate à pobreza abordada neste trabalho.

(Artigo recebido em julho de 2013. Versão final em setembro de 2013).

\section{Notas}

${ }^{1}$ A "primeira onda" de programas, do final da década de 1980 e início dos anos 1990, foi uma "marola", com os casos da Venezuela e Honduras. A partir da segunda metade dos anos 1990, a marola se transformou em um "tsunami". Em 1997 foi implementado o programa Oportunidades no México; em 2000 o programa Mi Familia na Nicarágua; em 2001 o programa colombiano Famílias en Acción e o equatoriano Bono Solidaridad-Bono de Desarrollo Solidario. Em 2002 foram implementados o Programa Chile Solidário e o Jefas y Jefes de Hogar Desocupados na Argentina; em 2003 foi a vez do Brasil implementar o Programa Bolsa Família. Outros casos de implementação de PTR: 2005: El Salvador, Programa Oportunidades (Red de Protección Social); Uruguai, Ingreso Ciudadano; Paraguai, Tekoporã; Ñopytyvo (na região do Chaco); R. Dominicana, Solidaridad; Peru, Juntos; 2006: Panamá, Red de Oportunidades (FonseCa e Viana, 2007, p.1507).

${ }^{2}$ Com relação às condicionalidades, o fato de serem estabelecidas em saúde e educação está associado à concepção de pobreza e resgate da cidadania, discutidas internacionalmente. Contudo, a determinação dos contornos dessas condicionalidades está dada pelas possibilidades estruturais e administrativas do País. Na opinião de Sposati (2011), há uma incongruência entre as condicionalidades de saúde e educação, visto que a primeira tem foco no nascimento e primeira 
infância (contexto materno-infantil) e a segunda apenas na segunda infância (público normativo do ensino fundamental). Isso é explicado pela estrutura da oferta das políticas, visto que a educação no Brasil não tem rede pública de atendimento de 0 a 3 anos e, assim, o controle educacional é deslocado para a segunda infância. Desse modo, a dificuldade de oferta de políticas sociais articuladas determina a construção possível da política pública de transferência de renda.

${ }^{3}$ Para mais informações sobre o debate recente sobre políticas sociais no Brasil, ver Fonseca e Leite (2009).

${ }^{4}$ Entende-se por “difusão-disseminação-transferência-aprendizagem” em políticas públicas o "(...) processo segundo o qual conhecimento (acerca das políticas públicas), arranjos administrativos, instituições etc., em um tempo ou lugar, são usados no desenvolvimento de políticas, arranjos administrativos e instituições em outro tempo e lugar" (Dolowitz e MARSH, 1996, p. 344, apud FARAH, 2008, p. 112).

${ }^{5}$ Para maiores detalhes sobre as correntes teóricas em análise de políticas públicas, ver Faria (2003) e Howlett, Ramesh \& Perl (2009).

6 “...sabe-se que o aprendizado ocorre quando os indivíduos assimilam uma informação nova, incluindo aquelas provenientes de experiências vividas, e utilizam essa informação posteriormente em suas ações. Portanto, podemos definir o aprendizado social como um tentativa deliberada de ajustar as metas ou técnicas de política considerando a experiência vivida (ou o conhect mento relevante sobre política) e informações novas. O aprendizado é demonstrado quando a política muda como resultado desse processo (HALL, 1993, p. 278, grifo nosso, tradução própria).

${ }^{7}$ Segundo Tomazini (2013), pode-se identificar historicamente três linhagens de paradigmas cognitivos no caso brasileiro - capital humano, segurança alimentar e renda incondicionada e, no caso mexicano, capital humano e renda incondicionada. Segundo o paradigma da renda incondicionada, "a pobreza seria o resultado da violação do direito a compartilhar a riqueza da nação. Os atores dessa coalizão defendem políticas universais, em oposição à focalização e às condicionalidades encerradas nos programas de luta contra a pobreza. Nesse sentido, as políticas de transferência de renda deveriam dar prioridade ao direito à renda que satisfaça um padrão de vida modesto, mas "socialmente aceitável"”" (Tomazini, 2013, p. 121). O conceito de segurança alimentar é histórico e polissêmico, mas ganha contornos de direitos a partir dos anos 1990. Segundo Belik (2003), "o direito de se alimentar regularmente e adequadamente não deve ser produto da benemerência ou resultado de ações de caridade mas, sim, prioritariamente, de uma obrigação que é exercida pelo Estado que, em última análise, é a representação da nossa sociedade. Vale lembrar também que o conceito de segurança alimentar continua em aberto e também está em discussão. Mais recentemente, já se fala também em soberania e sustentabilidade alimentar” (BELIK, 2003, p. 14). Ugá (2004) comenta o conceito de capital humano: "A teoria do capital humano afirma que as diferenças de rendas entre os indivíduos são influenciadas pelo capital humano (sobretudo educação) que cada um investe em si mesmo. O raciocínio básico pode ser assim sintetizado: (i) aumento da educação dos trabalhadores; (ii) estes terão suas habilidades e conhecimentos melhorados; (iii) quanto maiores as habilidades e conhecimentos, maior a produtividade do trabalhador; (iv) essa maior produtividade acaba gerando maior competitividade e, assim, maiores rendas para o indivíduo (UGÁ, 2004, p. 59).

${ }^{8}$ Neste trabalho, argumenta-se que, além das experiências de programas de transferência de renda federais, as experiências municipais dos anos 1990 influenciaram a conformação da trajetória do Programa Bolsa Família, por meio de processos de aprendizagem social nos termos de Hall (1993). Uma análise mais aprofundada nessa linha de argumentação encontra-se em LEITE, C. K. S e Peres, U. D. Paradigmas de desenvolvimento e disseminação de políticas: raízes federativas da 
criação do Programa Bolsa Família. Trabalho apresentado no $37^{\circ}$ Encontro AnUal DA AnPocs, Águas de Lindóia, 2013.

${ }^{9}$ Segundo González de La Rocha (2010), a utilização de ferramentas estatísticas, tanto para a pesquisa na área rural - Encuesta de Características Socioeconômicas de los Hogares Rurales (ENCASEH) quanto da área urbana - Encuesta de Características Socioeconômicas de los Hogares Urbanos (ENCASURB) -, foi determinante para os contornos do Progresa e Oportunidades. No entanto, as pesquisas depois mostraram-se com alcance limitado para manter a continuidade do processo de seleção das famílias necessitadas, que passou então a contar com a autosseleção e estudo aprofundado posterior da família como forma de inserção e complementação do cadastro estatístico.

${ }^{10}$ O Programa de Renda Mínima da Prefeitura do Município de São Paulo articulava-se ao Programa Bolsa Trabalho, Programa Começar de Novo, Programa Ação Coletiva de Trabalho (Operação Trabalho).

${ }^{11}$ A discussão sobre o investimento em um programa de renda mínima ou programas de indução econômica, como Banco do Povo, Economia Solidária, ou mesmo obras de investimento em infraestrutura urbana e habitação, era bastante acirrada no governo de São Paulo, em função da limitada capacidade do governo para investir diante do cenário de baixo crescimento econômico e dívidas herdadas de governos anteriores. Não existia no País experiência comparável em cobertura ao que se propunha fazer em São Paulo e, ainda, era uma dúvida quais seriam os resultados dessa política e sua possível sustentabilidade ou não. Diante disso, alguns grupos do governo apostavam que era melhor investir em programas de desenvolvimento econômico do que, nesse entendido, como meramente assistencial e pontual.

${ }^{12}$ Ver desenho do Programa Brasil sem Miséria, de 2011, que vincula transferência de renda à inclusão produtiva. "A miséria tem caras e necessidades diferentes conforme a região. A realidade no campo é uma, na cidade é outra bem diferente. Por isso, o Brasil Sem Miséria terá ações nacionais e regionais baseadas em três eixos: garantia de renda, inclusão produtiva e serviços públicos" (ver http://www.brasilsemmiseria.gov.br/apresentacao).

${ }^{13}$ Havia a proposta de $85 \%$ de frequência escolar como condicionalidade, do grupo ligado à educação, o que foi considerado exagerado e divergente em relação à LDB, que estabelece 65\% de frequência escolar como patamar mínimo (FonseCA, 2012).

${ }^{14}$ Argumentamos que as políticas de combate à pobreza no Brasil começaram a seguir naquele momento uma trilha de centralidade na coordenação entre as demais políticas, inclusive as econômicas. Há evidências em estudos de que os resultados de ativação dos mercados em localidades em que a população recebe as transferências de renda, por exemplo, têm sido incorporados aos discursos de pesquisadores e técnicos do governo para justificar o gasto social como instrumento de reação das autoridades à crise econômica que assola os países desenvolvidos já há alguns anos. Há vários trabalhos recentes produzidos por pesquisadores do Ipea que tratam da importância do gasto social na ativação de demanda efetiva e como fator de crescimento econômico. Ver: http://www.ipea.gov.br/portal/

${ }^{15}$ Conforme González de La Rocha (2010), o papel central das avaliações de impacto na formulação e implementação do programa mexicano reforça a hipótese da influência de técnicos de organismos multilaterais no processo de criação do programa Oportunidades. 


\section{Referências bibliográficas}

Banco Mundial. Relatório sobre o desenvolvimento mundial. A luta contra a pobreza. Washington, D.C., 2000-2001.

Bartholo, Letícia e Dutra, Ricardo R. Catastro Único de Programas Sociales: Brasil. In: Pontifícia Universidad Católica de Chile UC. Sistemas Integrados de Información Social: su rol en la protección social. Salesianos Impresores S. A PUCC - UC, 2011.

BELIK, Walter. Perspectivas para segurança alimentar e nutricional no Brasil. Revista Saúde e Sociedade, v.12, n.1, p.12-20, jan.-jun. 2003.

Campbell, John L. Ideas, Politics and Public Policy. Annual Review of Sociology, v. 28, p. 21-38, 2002.

Institutional analysis and the role of ideas in political economy. Theory and society, v. 27, n. 3, p. 377-409, 1998.

Coвo, Barbara. Políticas Focalizadas de Transferência de Renda: Contextos e Desafios. São Paulo: Ed. Cortez, 2012.

Сотта, T. C. S. Visões de proteção social e transferência de renda condicionada no Brasil e no México. 2009. Tese (doutorado) - Centro de Pesquisa e Pós-Graduação sobre as Américas, CEPPAC, Universidade de Brasília, Brasília, 2009.

DEACON, B. Eastern European welfare states: the impact of the politics of globalization. Journal of European Social Policy, 2000. Disponível em: www.esp.sagepub.com

Dulci, Otávio. Transferência de renda e política social: modelos e trajetórias institucionais na América Latina. In: Anais do 33 Encontro Da Anpocs, Caxambu, 2008.

FArah, Marta Ferreira Santos. Disseminação de Inovações e Políticas Públicas e Espaço Local. Organizações \& Sociedade, v. 15, nº 45, abril/junho 2008.

FARIA, C. A. P. Ideias, conhecimento e políticas públicas: um inventário sucinto das principais vertentes analíticas recentes. Revista Brasileira de Ciências Sociais, v. 18, $\mathrm{n}^{\circ}$ 51, fevereiro/2003.

Fonseca, Ana Maria Medeiros e VianA, Ana Luiza d’Ávila. Direito à saúde, atenção básica e transferências condicionadas de renda na América Latina. Ciência saúde coletiva, v.12, no 6, p.1505-1512, 2007.

Fonseca, Francisco e Leite, Cristiane Kerches da Silva. Políticas Sociais como Política de Estado. Le Monde Diplomatique Brasil, São Paulo, p. 6 e 7, nov. 2009.

GiL, Antonio C. Métodos e Técnicas de Pesquisa Social. 5 ed. São Paulo: Atlas, 1999.

GonzÁles de la Rocha, Mercedes. Pobreza, Progresa e Oportunidades: Una Mirada de Relativo Largo Plazo. In: Castro, Jorge Abrahão de e Modesto, Lúcia. Bolsa Família 2003 2010: avanços e desafios. Brasília: IPEA, 2010. cap. 8, p.169-202, 2010.

Hall, Peter. The movement from Keynesianism to monetarism: Institutional analysis and British economic policy in the 1970s. In: Steinmo, Sven; Thelen, Kathleen; Longstreth, Frank. Structuring politics: historical institutionalism in comparative analysis. New York: Cambridge University Press, p. 90-109, 1992. 
. Policy Paradigms, Social Learning and the State: The Case of Economic Policymaking in Britain. Comparative Politics, v. 25, n 3, april 1993, p. 275-296, 1993. Hayek, F. A. Von. Os Fundamentos da Liberdade. Brasília, Ed. UNB e São Paulo, Ed. Visão, 1983.

Howlett, Michael; Ramesh, M. \& Perl, Anthony. Studying public policy: policy cycles and policy subsystems. 3rd. ed. Oxford: Oxford University Press, 2009.

Justo, Carolina Raquel Duarte de Mello. Política de transferência de renda e cidadania no Brasil: implicações político-sociais dos Programas Municipais de Renda Mínima a partir do estudo comparativo dos casos de Campinas, Jundiaí, Santo Andre e Santos (19952006). Tese (Doutorado em Ciências Sociais) - Instituto de Filosofia e Ciências Humanas, Universidade Estadual de Campinas, Campinas, 2007.

Kingdon, John. Agendas, alternatives, and public policies. 3 ed. Nova York: Harper Collins, 2003.

Lautier, Bruno. O Consenso sobre as políticas sociais na América Latina, negação da democracia? Caderno CRH, Salvador, v. 23, no 59, p. 353-368, maio/agosto 2010.

LEITE, Cristiane Kerches da Silva e FONSECA, Francisco. Federalismo e políticas sociais no Brasil: impasses da descentralização pós-1988. Organizações \& Sociedade. v. 18, no 56, 2011.

Levy, Santiago. Pobreza y transición democrática en México. Washington, DC.: Brooking Institute Press, 2006.

Ensayos sobre desarrollo económico y social de México, México, F.C.E, 2004.

Matтos, Rubens de Araújo. As agências internacionais e as políticas de saúde nos anos 90: um panorama geral da oferta de ideias. Ciência e Saúde Coletiva, v. 6, nº 2, p. 377-389, 2001. Ministério do Desenvolvimento Social e Combate À Fome (MDS). Bolsa Família. Disponível em: MDS.gov.br. Acessado em: agosto de 2011.

Moraes, Reginaldo C. Reformas neoliberais e políticas públicas: hegemonia ideológica e redefinição das relações Estado-sociedade. Educação e Sociedade, v. 23, n. 80, p. 13-24, 2002.

Nascimento, Aline F. e Reis, Carlos Nelson. Os programas de transferência condicionada de renda na América Latina: especificidades de uma realidade que se mantém. Rev. Pol. Públ. São Luis, v. 13, n. 2, p. 183-193, jul./dez. 2009.

Pochmann, Marcio (org.) Desenvolvimento, Trabalho e Solidariedade - Novos caminhos para a inclusão social. São Paulo: Ed. Fundação Perseu Abramo/ Editora Cortez, 2002.

Silva e Silva, Maria Ozanira. O bolsa famiilia: problematizando questoPes centrais na poliìtica de transferência de renda no Brasil. Ciência e Saúde Coletiva, v. 12, no 6, p. 14291439, 2007.

SoAres, Fábio Veras. Para onde caminham os programas de transferência condicionada? As experiências comparadas do Brasil, México, Chile e Uruguai. In: CAstro, Jorge Abrahão; Modesto, Lúcia. Bolsa Família 2003 2010: avanços e desafios. v. 2. Brasília: Instituto de Pesquisa Econômica Aplicada, IPEA, 2010.

Sonres, Sergei, et al. Programas de Transferência Condicionada de Renda no Brasil, Chile e México: Impactos sobre a desigualdade. Texto para Discussão 1293. IPEA. Brasiilia, julho de 2007. 
Sposati, Aldaiza. Bolsa Família: um programa com futuros. In: CASTRO, Jorge Abrahão; Modesto, Lúcia. Bolsa Família 20032010: avanços e desafios. v. 2. Brasília: Instituto de Pesquisa Econômica Aplicada, IPEA, 2010.

. Tendências latino-americanas da política social pública no século 21. Rev. Katálysis [online]. v. 14, n.1, p. 104-115, 2011.

Steinmo, Sven and Thelen, Kathleen. Historical institutionalism in comparative politics. In: Steinmo, Sven, Thelen, Kathleen and Longstreth, Frank. Structuring politics: Historical institutionalism in comparative analysis. New York, Cambridge University Press, 1992. Tomazini, Carla Guerra. Disputas em torno das políticas de transferências de renda no Brasil e México: coalizões de causa e a consolidação do paradigma "capital humano". In: Tomazini, Carla Guerra e Lukic, Melina Rocha. As ideias também importam: abordagem cognitiva e políticas públicas no Brasil. Editora Juruá: Curitiba, 2013.

. La construction des politiques de transferts monétaires conditionnels: entre consensus et dissentiments. Une analyse de la lutte contre la pauvreté au Brésil et au Mexique. 2010. Tese (Doutorado) - Université Paris III - La Sorbonne Nouvelle, Institut des Hautes Études de l'Amérique Latine, Paris.

UGA, Vivian Domínguez. A categoria "pobreza" nas formulações de política social do Banco Mundial. Revista de Sociologia Política, n. 23, p. 55-62, 2004.

Valencia Lomelí, Enrique. La résurgence des politiques sociales au Mexique. Tiers-Monde, $\mathrm{n}^{\circ}$ $175,2003$.

Viana, Lúcio Hanai Valeriano. A influência do Banco Interamericano de Desenvolvimento na formulação de políticas públicas: análise das condições de financiamento do Programa de Reabilitação da Área Central no Município de São Paulo - Procentro. 2009. Dissertação (Mestrado) Escola de Administração de Empresas de São Paulo da Fundação Getúlio Vargas (EAESP), São Paulo.

Vergara, Sylvia C. Projetos e Relatórios de Pesquisa em Administração. São Paulo: Atlas, 1997. WeYLAND, Kurt. Learning from foreign models in Latin American policy reform. Washington, D.C. Woodrow Wilson Center Press. Baltimore Johns Hopkins University Press, 2004.

\section{Entrevistas}

Fonseca, Ana Maria Medeiros. Graduada em História e mestre em História Social e do Trabalho pela Universidade Estadual de Campinas (Unicamp), e doutora em História Social na área de família e relações de gênero pela Universidade de São Paulo (USP). Pesquisadora do Núcleo de Estudos em Políticas Públicas da Unicamp (Nepp/Unicamp), coordenou o programa Bolsa Família entre 2003 e 2004, e foi Secretária Executiva do Ministério do Desenvolvimento Social, em 2004. Foi ainda Analista de Políticas Sociais da Oficina do PNUD para a América Latina e o Caribe entre 2005 e 2006, e Analista de 
Políticas Sociais da Oficina Regional da FAO desde 2007. Tem atuado prioritariamente nas áreas de programas de transferência de renda, cidadania, pobreza, políticas públicas e família. Em 2011, assume a Secretaria Extraordinária para Superação da Extrema Pobreza (Sesep) no novo desenho organizacional do MDS. Entrevista realizada em 17/08/2012, em Campinas - SP (Nepp/Unicamp).

Quiroga, Junia. Doutora em Demografia; Diretora do Departamento de Avaliação do Ministério do Desenvolvimento Social (MDS). Entrevista realizada em 05/08/2011, em São Paulo-SP.

Ossandon, Mario. Diretor da Instituição responsável pela implementação do Chile Solidário e assessor do Parlamento em temas sociais; e UrRIOLA, Rafael, diretor no Chile 21. Entrevista realizada no dia 17/08/2011, em São Paulo-SP.

Sposati, Aldaíza. Ex-secretaria de Assistência Social do Município de São Paulo e coordenadora da Pós Graduação em Serviço Social da Pontifícia Universidade Católica (PUC/SP). Entrevista realizada em 19/08/2011, em São Paulo-SP. 


\section{Resumo - Resumen - Abstract}

\section{Origem e disseminação do Programa Bolsa Família: aproximações analíticas com o caso mexicano \\ Cristiane Kerches da Silva Leite e Ursula Dias Peres}

O objetivo deste texto é discutir a criação do Programa Bolsa Família a partir das correntes teóricas neoinstitucionalista e pós-positivista, tendo o caso mexicano como espelho. Argumenta-se que a onda latino-americana dos anos 1990 de programas de transferência de renda não implicou políticas homogêneas devido aos contextos políticos, sociais e institucionais de aprendizagem social (HaLL, 1993), às trajetórias das políticas nos países e ao embate de paradigmas e atores que influenciaram as políticas (CAMPBELL, 2002). Conclui-se, por meio da análise de dados qualitativos primários e secundários, que, a despeito de traços de semelhança que envolvem a descentralização administrativa no plano federativo e a hegemonia das ideias neoliberais nas políticas econômicas, os dois países produziram trajetórias de construção de programas de transferência de renda distintos. A interação entre atores políticos, sociais (domésticos e internacionais) e o papel das ideias em suas distintas categorias e seus efeitos nas políticas são relevantes nesta proposta de análise.

Palavras chave: disseminação de políticas; transferência de renda; paradigmas de políticas

Origen y diseminación del Programa Bolsa Familia en el contexto latinoamericano: un análisis comparativo

Cristiane Kerches da Silva Leite y Ursula Dias Peres

El objetivo del texto es debatir la creación del Programa Bolsa Familia desde el punto de vista de la diseminación de políticas, usando el caso mexicano como espejo. Se argumenta que la ola latinoamericana de los años 1990 de programas de transferencia de renta no ha resultado en políticas homogéneas debido a los contextos políticos, sociales e institucionales de aprendizaje social (HALL, 1993), a las trayectorias de las políticas en los países y al embate de paradigmas y actores que han influenciado las políticas (CAMPBELL, 2002). Se concluye que, a pesar de rasgos de similitud que involucran la descentralización administrativa en el plan federativo y la hegemonía de las ideas neoliberales en las políticas económicas, los dos países han producido trayectorias de construcción de programas de transferencia de renta distintos. La interacción entre actores políticos, sociales (domésticos e internacionales) y el papel de las ideas en sus distintas categorías y sus efectos en las políticas son relevantes en esta propuesta de análisis.

Palabras clave: diseminación de las políticas; transferencia de renta; paradigmas de políticas

Origin and dissemination of the Bolsa Família Program in Latin American context: a comparative analysis

\section{Cristiane Kerches da Silva Leite and Ursula Dias Peres}

This text aims to discuss the creation of Bolsa Familia Program, from the perspective of dissemination of policies, using Mexican's case as a comparison. It is argued that the LatinAmerican wave of income transfer programs, in the 1990s, did not produce homogeneous policies due to the political, social, and institutional contexts of social learning (HaLL, 1993); to the political trajectories in the countries; and to the paradigm and stakeholders clash that influenced such policies (CAMPBELL, 2002). One may conclude that, despite the resemblance traces concerning the administrative decentralization in the federal level and the hegemony of neoliberal ideas in 
economic policies, both countries produced trajectories for building different income transfer programs. The interaction between political and social (domestic and international) stakeholders and the role of ideas in their different categories and their effects in policies are relevant in this assessment proposal.

Keywords: policy dissemination; income transfer; policy paradigms

\section{Cristiane Kerches da Silva Leite}

É doutora em Ciência Política pela Universidade de São Paulo (USP), professora do curso de Gestão de Políticas Públicas e integrante do Programa de Pós-Graduação em Gestão de Políticas Públicas da Escola de Artes, Ciências e Humanidades da USP (EACH/USP). É autora do livro Processo Decisório no Brasil: o caso da Lei de Responsabilidade Fiscal (Ed. Hucitec, 2011).Contato: criskerches@gmail.com

Ursula Dias Peres

É doutora em Economia pela Escola de Administração de Empresas de São Paulo (EAESP/FGV), professora do curso de Gestão de Políticas Públicas e dos Programas de Pós Graduação em Mudança Social e Participação Política e em Gestão de Políticas Públicas da Escola de Artes, Ciências e Humanidades da USP (EACH/USP). Contato: uperes@usp.br 